Article

\title{
Canopy Transpiration and Stomatal Responses to Prolonged Drought by a Dominant Desert Species in Central Asia
}

\author{
Daxing Gu ${ }^{1}$, Quan Wang ${ }^{2, *}$ and Dennis Otieno ${ }^{3}$ \\ 1 Graduate School of Science and Technology, Shizuoka University, Shizuoka 422-8529, Japan; \\ gudaxing2008@163.com \\ 2 Faculty of Agriculture, Shizuoka University, Shizuoka 422-8529, Japan \\ 3 Department of Biological Sciences, Jaramogi Oginga Odinga University of Science \& Technology, \\ Bondo 4061-210, Kenya; dennis.otieno@uni-bayreuth.de \\ * Correspondence: wang.quan@shizuoka.ac.jp; Tel.: +81-54-2383683
}

Academic Editor: Luc Lambs

Received: 11 April 2017; Accepted: 2 June 2017; Published: 6 June 2017

\begin{abstract}
In arid and semiarid lands, canopy transpiration and its dynamics depend largely on stomatal sensitivity to drought. In this study, the sap flow of a dominant species, Haloxylon ammodendron growing in Central Asian deserts, was monitored using Granier-type sensors, from which the canopy stomatal conductance was derived. The responses of canopy transpiration and stomatal conductance to environmental variables during the second half of the growing season, when annual prolonged drought occurred, was analyzed for four continuous years, from 2013 to 2016. A soil water content (SWC) of 3\% was identified as the lower soil water threshold for this species, below which the plant lost the ability for stomatal regulation on water loss and suffered the risk of mortality. Above this threshold, the sensitivity of canopy transpiration to vapor pressure deficit, VPD (K), was linearly correlated with SWC, which mainly resulted from different stomatal behaviors at varying drought intensities. Stomatal sensitivity to $\operatorname{VPD}\left(\mathrm{m} / \mathrm{G}_{\text {sref }}\right)$ increased linearly with soil moisture deficit, inducing a shift from more anisohydric to a more isohydric stomatal behavior. The flexibility of stomatal behavior regarding soil drought was one key element facilitating the survival of $H$. ammodendron in such an extreme dry environment.
\end{abstract}

Keywords: transpiration; stomatal sensitivity; isohydric; drought; desert; dysfunction

\section{Introduction}

Central Asia is dominated by arid and semi-arid lands and is one of the most vulnerable regions to climate change [1]. With increasing global air temperatures, glaciers in this region show a declining trend in volume [2,3], which will ultimately result in intensification of water deficit during the hot and dry summer periods [4], since they are the primary regulator of seasonal variability of regional runoff and a buffering water source for summer. Based on regional climate models, the annual temperature and annual precipitation in northwest of China are predicted to increase by $2.0^{\circ} \mathrm{C}$ and $19 \%$, respectively, under the scenarios of double atmospheric $\mathrm{CO}_{2}$ concentrations [3]. For Central Asia, area-averaged annual mean surface air temperature and precipitation is predicted to increase by $3.18^{\circ} \mathrm{C}$ and $1.3 \%$, respectively, by 2050 , but with a more heterogeneous seasonal distribution. Thus, summers are likely to experience a $3.55^{\circ} \mathrm{C}$ increase in temperature and $2.3 \%$ decline in precipitation [5]. These predictions generally point to drier summers or plant growing seasons, which has also been demonstrated by an observation data-based analysis [6]. Due to poor historical observational data archives in such extensive deserts, large uncertainties exist in current projections [3]. Drought, however, 
remains the major limitation to ecosystem processes and function, and this is expected to continue in the coming decades.

Vegetation water use is tightly coupled to ecosystem productivity and sensitivity to drought $[7,8]$. Plant hydraulic failure resulting from excessive transpiration water loss is a major cause of tree mortality during drought [9-11]. Assessment of the stability of arid ecosystems in light of ongoing climate change, therefore, requires a mechanistic understanding of transpiration water loss in the extreme drought environment, particularly for dominant vegetation.

Stomata are the main channels for water exchange between vegetation and the atmosphere. Thus, drought-environmental sensing and the regulation of water loss are accomplished by the stomata. Among the environmental variables, atmospheric vapor pressure deficit (VPD) is the main factor driving leaf transpiration and has a strong influence on stomatal conductance [12]. Stomatal sensitivity to VPD is a valuable tool that plants employ in order to maintain stable tissue water status under drought environments $[13,14]$. Previous studies have shown that stomatal sensitivity to VPD is variable among species and also among different environmental conditions [15,16]. For instance, Bourne et al. [17] found that Eucalyptus species originating from more arid climates had a lower stomatal sensitivity to VPD and that transpiration declined less during a progressive drought than those from humid climates, where water deficit was rare. Similarly, Cunningham [18] found that tropical species, with no growing season's drought, showed higher stomatal sensitivity to VPD than the temperate species, which experienced frequent water stress during the growing season. Rogiers et al. [16] reported heightened stomatal sensitivity of a grapevine cultivar (Vitis vinifera) to VPD in drier soils. Most of the previous field studies were, however, conducted under sporadic drought or with short-term drought spans. In arid and semiarid regions in Central Asia, where drought persists for several months, almost on an annual cycle, knowledge of plant stomatal response to VPD under different degrees of drought is necessary in order to predict how transpiration will respond to continuous, long-term drought events and for evaluating ecosystem vulnerability under climate change.

Desert is one of the primary ecosystems in Central Asia. With extremely low precipitation and high atmospheric vapor demand, vegetation here is on the verge of extinction due to increasing climateand human-related influences [19]. Haloxylon ammodendron (CA Mey.) Bunge is the dominant shrub in deserts located in Central Asia and plays a key role in preventing the vulnerable desert ecosystems here from degeneration. Previous studies revealed that daily transpiration of H. ammodendron was correlated with VPD, photosynthetic photon flux density (PPFD) and air temperature $\left(\mathrm{T}_{\text {air }}\right)$ during its growing season [20]. From the same species, Zheng and Wang [21] observed varying branch and whole-tree transpiration responses to climate factors and concluded that canopy scale patchiness existed in this desert species. Due to a pronouncedly higher evaporation than precipitation during the growing season, soil water content decreases continuously during summer and autumn. As a result, soil is drier in the second half of the growing season than in the first half [22,23]. Thus, H. ammodendron suffers the highest risk of dysfunction during the second half of the growing season, and its canopy transpiration response to environment and underlying stomatal regulation at this time determine its survival. Little is, however, known about its stomatal response to environmental variables and the regulation of transpiration water loss during the prolonged drought condition.

The current study examined (1) environmental controls on transpiration of H. ammodendron at intra-annual and inter-annual scales during prolonged droughts; (2) the influence of the degree of soil drought on canopy transpiration response to climate factors; and (3) inter-annual variations of canopy stomatal response to VPD under progressive drought.

\section{Materials and Methods}

\subsection{Study Site}

The study was conducted in the Beishawo experimental plot $\left(44^{\circ} 25^{\prime} 54^{\prime \prime} \mathrm{N}, 87^{\circ} 54^{\prime} 9^{\prime \prime}\right.$ E) located on the southern edge of Gurbantünggüt desert in northwest China and Central Asia. The plot was 
established in 2009. It has a flat topography and is dominated by homogeneous silver sand soil. Mean soil $\mathrm{pH}$ is 8.52 and the total salt content is $0.25-0.69 \mathrm{mg} \mathrm{g}^{-1}$. Continental arid temperate climate determines the large seasonal temperature range in this site. Mean daily maximum air temperature during summer is $>40^{\circ} \mathrm{C}$, while the mean daily minimum temperature in winter is $<-20^{\circ} \mathrm{C}$. The mean annual temperature is $7.5^{\circ} \mathrm{C}$. Long-term (1985-2010) annual average precipitation is $163 \mathrm{~mm}$ [24] and snowfall in winter is the main water source for the budding shrubs and short-lived grasses. Contrary to the low precipitation, the mean annual pan evaporation is approximate $2000 \mathrm{~mm}$.

H. ammodendron is the dominant species on the site. Short-lived and shallow-rooted herbaceous species e.g., Erodium oxyrrhynchum, Ceratocarpus arenarius and Alyssum linifolium, occur in spring in response to increased soil moisture input from the melted snow, but die out in early summer. The mean canopy coverage and density of $H$. ammodendron in this study site is estimated at $16 \%$ and 584 stems ha $^{-1}$, respectively $[20,21]$. The mean canopy height is $2 \mathrm{~m}$, while the mean basal diameter is $6.4 \mathrm{~cm}$. Coverage of sapwood area is appropriately $0.77 \mathrm{~m}^{2} \mathrm{ha}^{-1}$, estimated according to an inventory done by Zheng and Wang [21]. The growing season of H. ammodendron at this site usually starts at the end of April and ends in late October, while that of understory grasses usually last from April to June.

\subsection{Environmental Variables}

An automatic weather station (Vantage Pro2 ${ }^{\mathrm{TM}}$, Davis Instruments, Hayward, CA, USA) was installed on the study site to continuously record air temperature $\left(\mathrm{T}_{\text {air }}\right)$, relative humidity $(R H)$, wind speed and direction, precipitation. A quantum sensor (Li190SB, Campbell Scientific, Inc., Logan, UT, USA) was used to measure photosynthesis photo flux density (PPFD) at $3 \mathrm{~m}$. Volumetric soil moisture content (SWC) was measured by soil moisture sensor (ThetaProbe, Delta-T Devices Ltd., Cambridge, UK) at $20 \mathrm{~cm}$ in depth. Data was sampled every $1 \mathrm{~min}$ and $10 \mathrm{~min}$ averages recorded by data logger (DT80, Thermo Fisher Scientific Australia Pty Ltd., Scoresby, Australia). Atmosphere pressure $\left(\mathrm{P}_{\text {air }}\right)$ was provided by an eddy covariance system (Li-7500, Licor Inc., Lincoln, NE, USA) installed at an $11 \mathrm{~m}$-high tower, which was $50 \mathrm{~m}$ away from the weather station. Atmospheric vapor pressure deficit (VPD) was then calculated using 10-min averages of air temperature and relative humidity according to Campbell and Norman [25]:

$$
\mathrm{VPD}=a \times e^{\frac{b \times T_{a i r}}{T_{a i r}+c}} \times(1-R H)
$$

where $T_{\text {air }}$ is air temperature $\left({ }^{\circ} \mathrm{C}\right), R H$ is atmosphere relative humidity $(\%)$ and a, $b, c$ are constants set to $0.611,17.502$ and 240.97 , respectively.

\subsection{Canopy Transpiration and Stomatal Conductance}

Six custom-type Thermal Dissipation Probes (TDP) $[21,26]$ were used to monitor stem sap flow in the $20 \mathrm{~mm}$ depth of the conducting sapwood at approximate $30-50 \mathrm{~cm}$ above the ground in six different individual trees. The diameters ranged from 5 to $20 \mathrm{~cm}$, being representative of the stem size distribution in this study site. All sensors were installed on the north side and covered with a plastic box and one layer of foil and reflective film to protect against mechanical and thermal disturbance and prevent rain water. The upper probe was continuously heated with constant power of $0.2 \mathrm{~W}$ and signals between heated and reference probes were sampled every $1 \mathrm{~min}$ and mean values recorded by data logger (DT80, Thermo Fisher Scientific Australia Pty Ltd.) at interval of $10 \mathrm{~min}$, which was synchronous with environment measurement. Sap flow density in the stem sapwood was computed according to Granier [26] and the sapwood area-weighted averages determined. Individual sapwood area was estimated according to an allometric equation between stem diameter $(D, \mathrm{~cm})$ and sapwood area $\left(\right.$ As in $\left.\mathrm{cm}^{2}\right)$ established by Zheng and Wang [21] in the same site:

$$
\text { As }=0.39 \times D^{1.73}\left(R^{2}=0.98, n=32\right)
$$


The weighted average of sap flow density was up-scaled to canopy transpiration per ground area $\left(\mathrm{T}_{\mathrm{r}}\right)$ based on sapwood coverage of H. ammodendron in this study site. $\mathrm{T}_{\mathrm{r}}$ was used to calculate canopy stomatal conductance by inverting Penman-Monteith (P-M) model according to Granier et al. [27]:

$$
\mathrm{G}_{\mathrm{s}}=\frac{\gamma \lambda \mathrm{T}_{\mathrm{r}}}{\rho_{\mathrm{a}} \mathrm{C}_{\mathrm{p}} \mathrm{VPD}}
$$

where $G_{s}$ is the canopy stomatal conductance for water vapor $\left(\mathrm{m} \mathrm{s}^{-1}\right), \gamma$ is the psychrometric constant $\left(\mathrm{kPa} \mathrm{K}^{-1}\right), \lambda$ is latent heat of vaporization (energy required per unit mass of water vaporized $\left(\mathrm{J} \mathrm{g}^{-1}\right)$, $\rho_{\mathrm{a}}$ is dry air density $\left(\mathrm{kg} \mathrm{m}^{-3}\right) . \mathrm{C}_{\mathrm{p}}$ is the specific heat of air at constant pressure $\left(\mathrm{J} \mathrm{kg}^{-1} \mathrm{~K}^{-1}\right)$, and VPD is atmospheric vapor pressure deficit $(\mathrm{kPa}) . \mathrm{G}_{\mathrm{s}}$ can then be converted to molar units according to ideal gas law [28]. With needle-like leaves (assimilating branch) and sparse, open and short canopy, $H$. ammodendron canopy is well-coupled to the surrounding atmosphere and there is no vertical gradient in VPD throughout the canopy. Thus Equation 3 is applicable in this study.

\subsection{Data and Statistical Analysis}

According to the annual water cycle dynamic and soil moisture conditions at this study site, the second half of the growing season from the first of August to early October when atmosphere temperature higher than $10^{\circ} \mathrm{C}$ was defined as annual prolonged drought period in this study and data during this period from 2013 to 2016 was then used for further analysis. Transpiration of H. ammodendron and PPFD were accumulated and VPD was averaged daily during daytime (when incoming PPFD $\geq 40 \mu \mathrm{mol} \mathrm{m}^{-2} \mathrm{~s}^{-1}$ ) while rainfall was accumulated and SWC was averaged every entire day during study periods. One-way ANOVA with Duncan test was performed to show annual difference in transpiration and environmental factors. The relationships between transpiration and environmental variables were fitted with liner and quadratic functions except the relationship between $G_{S}$ and VPD, which was fitted with a linear logarithmic equation proposed by Oren et al. [10] under conditions with high radiation (daily average PPFD $>200 \mu \mathrm{mol} \mathrm{m}^{-2} \mathrm{~s}^{-1}$ ):

$$
\mathrm{G}_{\mathrm{s}}=\mathrm{G}_{\text {sref }}-\mathrm{m} \times \ln (\mathrm{VPD})
$$

where $G_{\text {sref }}$ is the $G_{s}$ when VPD $=1 \mathrm{kPa}$ and $m$ is the stomatal sensitivity to VPD. All statistical analysis was conducted with $p<0.05$ as a threshold for statistical significance.

\section{Results}

\subsection{Soil Moisture and Microclimate}

General decreasing trends of all the climate variables from DOY 210 to DOY 290 can be distinguished during the four-year study period between 2013 and 2016, even though apparent day to day fluctuations also occurred (Figure 1a-h). Mean daily PPFD was estimated at 28.2, 33.2, 26.1 and $26.0 \mathrm{~mol} \mathrm{~m}^{-2} \mathrm{~d}^{-1}$ while the respective daily VPD values were $2.5,2.6,2.0$ and $2.7 \mathrm{kPa}$, respectively, during the four years. During the study period, accumulative annual rainfall was 44.6, 22.0, 58.8 and $42.8 \mathrm{~mm}$ from 2013 to 2016, respectively. During the same periods, volumetric SWC varied from $4.3 \%$ to $3.3 \%$ in $2013,2.5 \%$ to $1.8 \%$ in $2014,3.7 \%$ to $2.7 \%$ in 2015 and $5.3 \%$ to $3.3 \%$ in 2016 , with the respective mean values of 3.7\%, 2.1\%, 3.1\% and 4.5\% in 2013, 2014, 2015 and 2016 (Figure 1i-1). Changes in volumetric SWC among the years were significant $(p<0.001)$. The inter-annual variations of PPFD and VPD during the study periods (among the four years) were significant $(p<0.05)$, while PPFD among 2013, 2015 and 2016 and VPD between 2013, 2014 and 2016 was not significantly different $(p>0.05)$. 


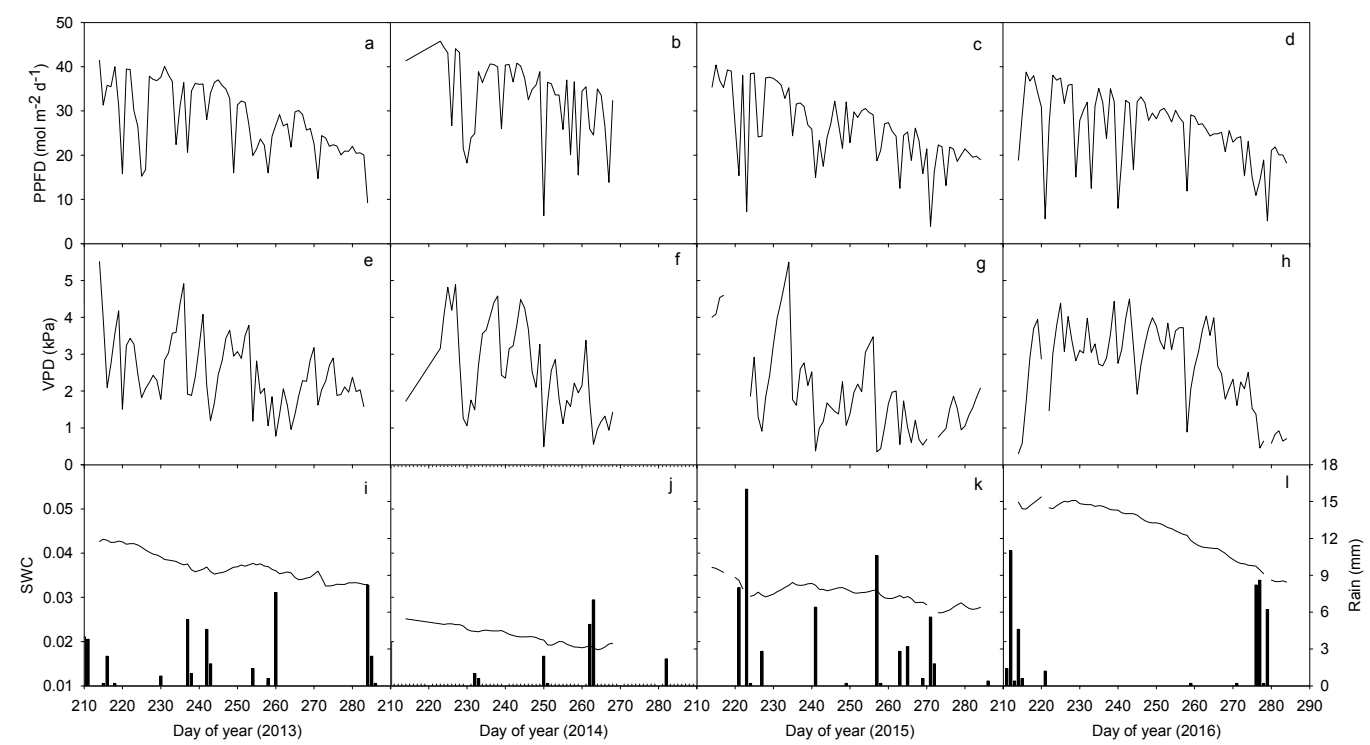

Figure 1. Daily photosynthetic photon flux density (PPFD, a-d), vapor pressure deficit (VPD, e-h), rainfall and volumetric soil water content $(S W C, \mathbf{i}-1)$ during the second half of the growing season (August 1 to early October) between 2013 and 2016. PPFD and VPD were computed every day during daytime when PPFD $\geq 40 \mu \mathrm{mol} \mathrm{m} \mathrm{m}^{-2} \mathrm{~s}^{-1}$ while rainfall and SWC were computed every whole day.

\subsection{Canopy Transpiration}

Annual patterns in transpiration of H. ammodendron were variable (Figure 2). Due to equipment failure, only approximate one-month data were available in 2013 and the mean daily transpiration was $0.044 \mathrm{~mm} \mathrm{~d}^{-1}$. The average daily transpiration in 2014 was $0.028 \mathrm{~mm} \mathrm{~d}^{-1}$. In 2015, transpiration of $H$. ammodendron decreased from $0.044 \mathrm{~mm} \mathrm{~d}^{-1}$ to $0.010 \mathrm{~mm} \mathrm{~d}^{-1}$, with an average value of $0.026 \mathrm{~mm} \mathrm{~d}^{-1}$. Daily transpiration in 2016 remained high at $0.070 \mathrm{~mm} \mathrm{~d}^{-1}$ before decreasing markedly to $0.009 \mathrm{~mm} \mathrm{~d}^{-1}$ at the end of the growing season, with the average daily rates of $0.049 \mathrm{~mm} \mathrm{~d}^{-1}$. Statistical analysis showed that the inter-annual variations in daily transpiration among the four years were significant $(p<0.001)$. Daily transpiration in 2013 and 2016 was significantly higher than in both 2014 and $2015(p<0.05)$. Differences in transpiration between 2013 and 2016 and between 2014 and 2015 were not significant $(p>0.05)$.

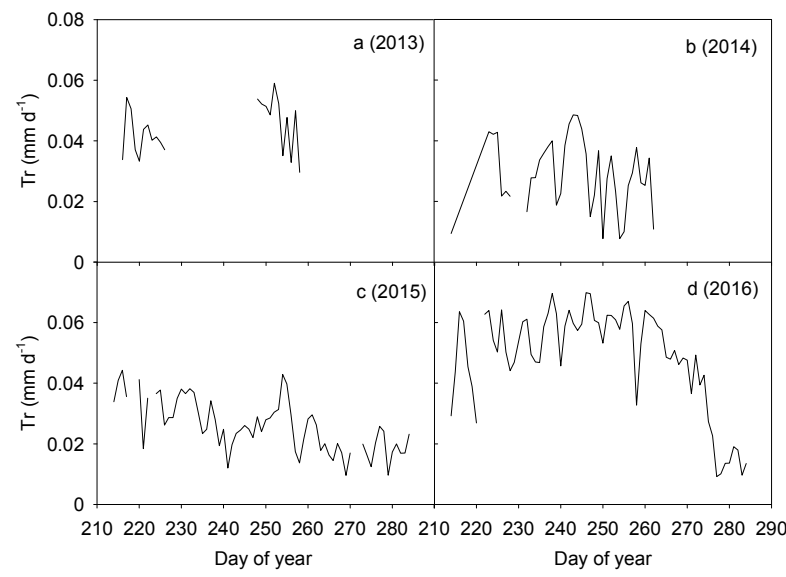

Figure 2. Variations in daily cumulative canopy transpiration per ground area (PPFD $\geq 40 \mu \mathrm{mol} \mathrm{m}^{-2} \mathrm{~s}^{-1}$ ) during the second half of the growing season (1 August to early October) when air temperature $>10^{\circ} \mathrm{C}$ from 2013 to 2016 (a-d). Data gaps in 2013 resulted from equipment failure while data gaps in 2014 were due to low air temperatures $\left(<10^{\circ} \mathrm{C}\right)$ at the end of the measurement period. 


\subsection{Response of Daily Canopy Transpiration to Environmental Variables}

Transpiration response patterns of $H$. ammodendron to environmental variables were clearly different in different years and with different environmental variables (Figure 3a-c). Daily transpiration during the study periods increased linearly with PPFD $(p<0.05)$ in 2014, 2015 and 2016, but not in 2013 ( $p>0.05$, Figure 3a). In all the years, daily canopy transpiration increased linearly with VPD $(p<0.01$, Figure $3 \mathrm{~b})$. The sensitivity of canopy transpiration to VPD (K, defined as the slope of linear regression between daily $\mathrm{T}_{\mathrm{r}}$ and VPD) increased linearly with the mean daily SWC $(p<0.001)$ when the average SWC of the second half growing season was above 3\% (including fitted K in 2013, 2015 and 2016, Figure 4). The fitted $\mathrm{K}$ in the driest year (2014) fell inside the range of those found in the other three years (Figure 4). Daily transpiration in both 2015 and 2016 were significantly correlated with SWC $(p<0.01)$, while that in 2013 and 2014 was not significant $(p>0.05$, Figure 3c). Relationship between daily canopy transpiration and SWC in 2016 could be described by a quadratic function $\left(y=-324.38 x^{2}+29.98 x-0.63, R^{2}=0.77\right)$ while that in 2015 was a linear function $(y=2.0 x-0.04$, $\left.R^{2}=0.29\right)$. Although intra-annual transpiration response to SWC differed among the four years, the inter-annual transpiration increased linearly with increasing SWC at SWC $>3 \%$, but it was stable at SWC $<3 \%$ (Figure 3c). The correlation between inter-annual canopy transpiration and SWC was significant $(p<0.001)$.

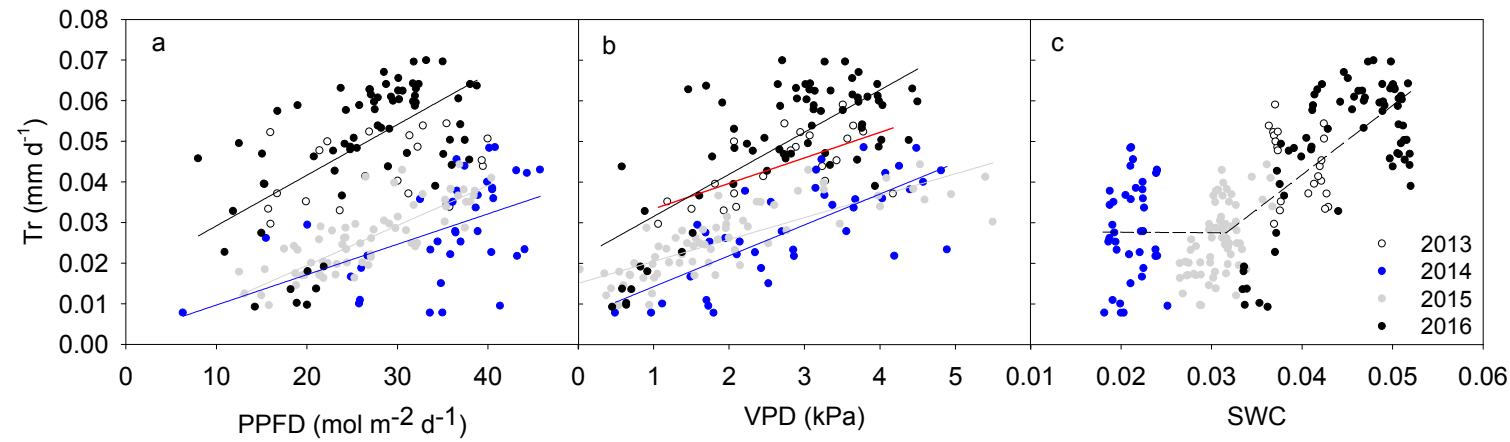

Figure 3. Responses of daily canopy transpiration $\left(T_{r}\right)$ to daily accumulative photosynthetic photon flux density (PPFD, a), mean vapor pressure deficit (VPD, $\mathbf{b}$ ) and mean volumetric soil water content (SWC, c) during the half of the growing season (1 August to early October) from 2013 to 2016. Lines in the first two figures were fitted with linear functions in each of the monitored four years. Line colors represent different years while the discontinuous line in the last figure was fitted with a linear function based on all data in the four years.

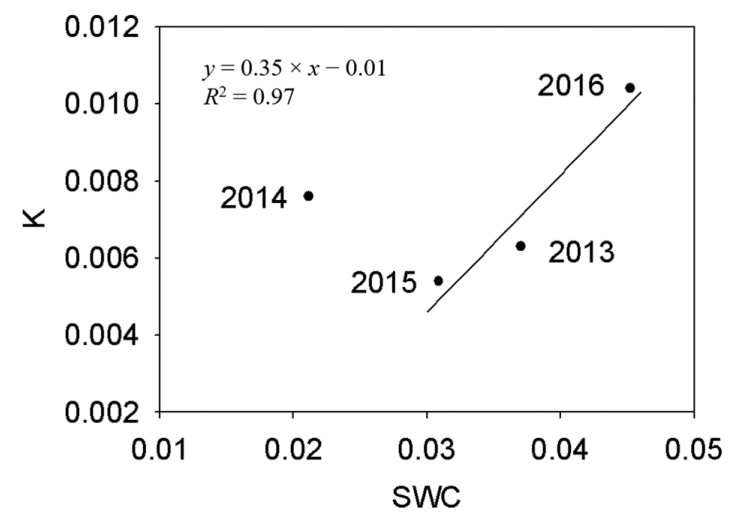

Figure 4. Relationship between annual mean volumetric soil water content (SWC) and transpiration sensitivity to VPD (K) from 2013 to 2016. Transpiration sensitivity to VPD (K) was defined as the slope of linear regression between daily $\mathrm{T}_{\mathrm{r}}$ and VPD. The data were fitted with a linear function between $\mathrm{K}$ and annual average SWC at SWC $>3 \%$. 


\subsection{Response of Canopy Stomatal Conductance to VPD in Different Years}

As shown in Figure 5a, during the second half of the growing season in each of the four years, daily canopy stomatal conductance in 2014 varied from 0.54 to $2.33 \mathrm{mmol} \mathrm{m}^{-2} \mathrm{~s}^{-1}$, with a mean rate of $1.23 \mathrm{mmol} \mathrm{m}^{-2} \mathrm{~s}^{-1}$, which was significantly lower than in the other years $(p<0.05)$. Mean daily scale daytime canopy stomatal conductance in 2013, 2015 and 2016 were 2.30, 2.10 and $2.54 \mathrm{mmol} \mathrm{m}^{-2} \mathrm{~s}^{-1}$, respectively. There were no significant differences among those 3 years $(p>0.05)$.

Daily stomatal conductance was significantly correlated with daily mean VPD in each year, expressed by linear logarithmic functions $(p<0.05)$. Stomatal sensitivity to VPD (slope of fitted function, $\mathrm{m})$ and reference stomatal conductance $\left(\mathrm{G}_{\mathrm{s}}\right.$ when VPD $\left.=1 \mathrm{kPa}, \mathrm{G}_{\text {sref }}\right)$ were lowest in the driest year of 2014. In addition, $\mathrm{m} / \mathrm{G}_{\text {sref }}$ was 0.46, 0.22, 0.52 and 0.35 in 2013, 2014, 2015 and 2016, respectively. The $\mathrm{m} / \mathrm{G}_{\text {sref }}$ decreased linearly with increasing annual average SWC when annual average SWC $>3 \%(p<0.001$, Figure $5 b)$.
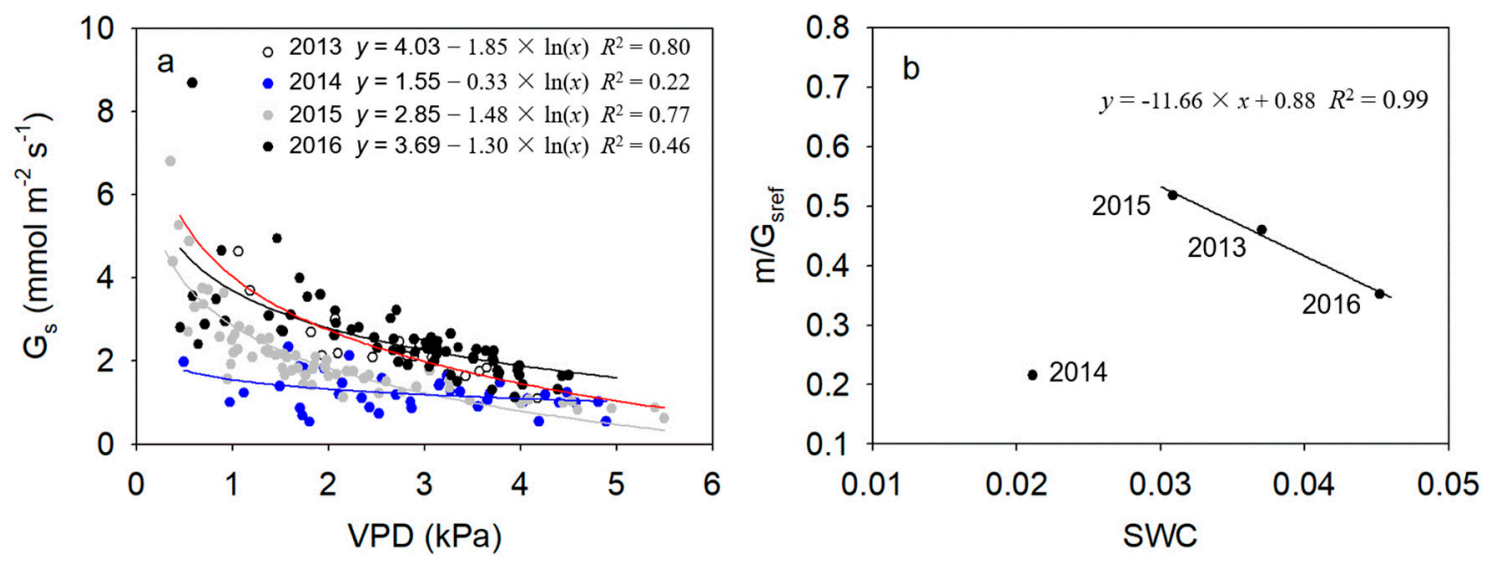

Figure 5. Relationships between mean daily canopy stomatal conductance $\left(\mathrm{G}_{\mathrm{S}}\right)$ and daily average vapor pressure deficit (VPD) under conditions of high radiation (daily average PPFD $>200 \mu \mathrm{mol} \mathrm{m}^{-2} \mathrm{~s}^{-1}$ ) during the second half of the growing season (1 August to early October) from 2013 to 2016 (a) and inter-annual relationship between the ratio of stomatal sensitivity to reference stomatal conductance $\left(\mathrm{m} / \mathrm{G}_{\text {sref }}\right)$ and annual average volumetric soil water content (SWC) (b).

\section{Discussion}

\subsection{Soil Drought Intensity Decides the Response of Canopy Transpiration to Climate}

Plant transpiration is a physiological process that is mainly controlled by surrounding environmental variables, particularly solar radiation, soil water availability and VPD and the physiological status of the leaf, mainly the leaf water status [29,30]. Daily canopy transpiration of H. ammodendron increased linearly with PPFD in 2014, 2015 and 2016. This is consistent with the results found by Zheng and Wang [21]. Similarly, canopy transpiration increased linearly with increasing VPD in all the years and the sensitivity of daily transpiration to VPD (K- defined as the slope of fitted linear function between $\mathrm{T}_{\mathrm{r}}$ and SWC), increased linearly with annual average SWC, except during the driest year (2014). The linear correlation between canopy transpiration and VPD was similar to that reported previously under similar drought conditions [31], but differed from those found in other relatively moist conditions, in which saturated transpiration occurred at high VPD [21,32]. This is likely due to decreased sensitivity (response magnitude) of stomatal conductance to VPD during prolonged drought. The linear correlation between SWC and transpiration sensitivity to VPD clearly indicated the influence of environmental variables on canopy transpiration. Similar results have also been reported by Chen et al. [33], in which Ziziphus jujube had decreased sap flow sensitivity to VPD with increasing soil water stress in semiarid Northwest China. These results indicated that soil 
water availability was a fundamental variable affecting plant water physiology in arid and semiarid ecosystems [34,35].

Intra-annual H. ammodendron transpiration was significantly and linearly correlated with SWC only in 2015, suggesting there was no consistent intra-annual direct relationship between them. However, on a long-term scale (inter-annual scale), the daily canopy transpiration increased linearly with increasing SWC when SWC was higher than 3\%. This demonstrated that in the second half of the growing season in each year, associated with prolonged drought, SWC remained relatively low and could not induce any variations in canopy transpiration. Patterns of canopy transpiration during this period were mainly controlled by VPD, while the magnitudes (transpiration sensitivity to VPD) were determined by SWC levels. Thus, the underlying indirect regulation of SWC on canopy transpiration only become apparent at an inter-annual scale, when the inter-annual SWC varied significantly, something that was not apparent in the short term. Although different transpiration responses to VPD have been found in contrasting soil water conditions in previous studies [31,33], the long-term relationship between SWC and canopy transpiration response to VPD has not been well investigated, mainly due to insufficient available data. Our results suggest the need for long-term (inter-annual) monitoring of the interaction between plant transpiration and environmental variables, in order to accurately evaluate ecosystem functions and vulnerability in the arid lands, which suffer frequent and extended droughts.

The linear increase of inter-annual transpiration with increasing soil water availability when the SWC $>3 \%$ suggested that, on a long-term scale, canopy transpiration of H. ammodendron was limited by restricted soil water availability during a prolonged drought. Moreover, strong inter-annual transpiration response to shallow SWC $(20 \mathrm{~cm}$ depth) indicated that shallow soil water was also one of the main water sources for $H$. ammodendron. Xu et al. [22] investigated natural root distribution of $H$. ammodendron in the same desert and found that more than $90 \%$ of feeder roots are located within 0 to $0.9 \mathrm{~m}$ top soil layer. $\mathrm{Xu}$ and $\mathrm{Li}$ [36] found that transpiration and leaf water potential were sensitive to rain pulse events and precipitation-derived upper soil water was the main water source of H. ammodendron. The results from both studies are consistent with ours.

An interesting finding of this study was that when SWC was $<3 \%$, the annual canopy transpiration of $H$. ammodendron was unresponsive to SWC, demonstrating that $3 \%$ was the lowest threshold of SWC for this species, below which it was likely to suffer high risk of mortality. The relative stable canopy transpiration when SWC was less than 3\% hence reflects the lowest transpiration rate of $H$. ammodendron to allow for the necessary carbon assimilation and leaf temperature regulation (through evaporative cooling), both of which are necessary for plant survival in the desert conditions $[9,37,38]$. Hartmann et al. [11] reported that transpiration of Norway spruce (Picea abies) stabilized at low value before mortality occurred, when relative extractable soil water content was approaching zero under extreme drought. Similarly, transpiration of piñon (Pinus edulis) was projected to have a weak response to SWC and precipitation pulses before mortality under prolonged drought, based on mixed effects models [39].

\subsection{Soil Drought Intensity Decides Stomatal Regulation Ability for Water Loss}

Stomata are the main channels through which $\mathrm{CO}_{2}$ and $\mathrm{H}_{2} \mathrm{O}$ exchange between plant and atmosphere occurs. Stomatal conductance $\left(\mathrm{G}_{\mathrm{S}}\right)$ is, therefore, a critical physiological function balancing plant transpiration and assimilation. $\mathrm{G}_{\mathrm{s}}$ is markedly affected by environmental conditions and its regulation of hydraulic homeostasis was species-dependent [40]. Based on the magnitude at which the water status variation was maintained through stomatal regulation among various environment conditions, the terms of isohydric and anisohydric were used to describe stomatal regulation on transpiration in previous studies [13]. Isohydric refers to tight stomatal regulation on plant water loss that maintains a relatively constant leaf water potential regardless of soil moisture conditions, whereas less stomatal regulation on transpiration, leading to considerable water status variation under varying soil water conditions, is anisohydric [41]. Although the terms have been previously used to 
describe species- or variety-specific stomatal function, recent reports showed inconsistent stomatal behaviors (isohydric and anisohydric) for certain varieties [42,43]. In our study, $\mathrm{G}_{\mathrm{s}}$ of H. ammodendron was significantly correlated with VPD and could be described with linear logarithmic functions each year. In 2015 when the annual average SWC as low as $3 \%$, the calculated $m / G_{\text {sref }}$ was 0.52 , still close to that of theoretical ratio (0.60) derived from a hydraulic model which assumes perfect stomatal regulation of constant leaf water potential with respect to VPD [15], indicating that H. ammodendron imposes a tight stomatal regulation on water loss (more isohydric) when the annual average SWC was as low as 3\%. With increasing annual average SWC in the second halves of growing seasons, $m / G_{\text {sref }}$ decreased linearly from 0.52 in 2015 to 0.35 in 2016, when soil moisture was highest among the four years, demonstrating a relative slack stomatal regulation on water loss (more anisohydric) during years when SWC was relative relaxed. $\mathrm{Xu}$ et al. [44] found that midday leaf water potential of $H$. ammodendron showed considerable response to rain events when soil water content was more than $3 \%$, indicating that $H$. ammodendron behaved more ansiohydrically, consistent with our results. Furthermore, Zhang et al. [43] reported that one grape variety (Vitis Vinifera) showed more isohydric-like stomatal behavior under low SWC but switched to anisohydric-like behavior with increasing SWC, which was consistent with stomatal strategies of $H$. ammodendron during prolonged drought. Such inter-annual progressive variation of stomatal behavior from more anisohydric to more isohydric under decreasing SWC during a prolonged drought indicated that the species had flexible stomatal regulation ability on transpiration. Adjustment of stomatal ability in regulating transpiration according to soil water availability is the main mechanism for plants to make a balance between maximizing production when soil moisture was attractable and keeping hydraulic security when soil moisture was more limited [41,43]. This is critical for the survival of H. ammodendron in the harsh desert environment associated with extended periods of drought each year. Although mechanisms driving stomatal regulation under varying soil moisture conditions are less known, Domec and Johnson [41] reported that the variation of hydraulic signal might allow stomatal function of some species to switch between more isohydric and more anisohydric.

As the H. ammodendron canopy is sparse and boundary conductance between canopy and atmosphere is large enough to be neglected, canopy transpiration was mainly controlled by stomatal conductance [44]. The decreasing stomatal sensitivity to VPD ( $\left.\mathrm{m} / \mathrm{G}_{\text {sref }}\right)$ introduced relative high stomatal conductance and transpiration rates. Thus, increasing annual transpiration sensitivity to VPD (K) found in this study when SWC $>3 \%$ resulted mainly from the decreased stomatal sensitivity to VPD in wetter soils.

During the driest year (2014) when SWC was less than 3\%, H. ammodendron had the lowest mean daily canopy stomatal conductance and stomatal sensitivity $\left(\mathrm{m} / \mathrm{G}_{\text {sref }}\right)$. Even so, canopy transpiration in 2014 was comparable to that in 2015 when SWC was higher, indicating the failure of stomatal regulation on water loss, which largely relate to hydraulic conductance [44]. However, following the driest year (2014), stomatal regulation on transpiration recovered in the following two relatively wetter years (2015 and 2016), indicating that the whole plant's hydraulic apparatus was preserved, although stomata failed to regulate water conservation in an extreme drought year (2014). The capacity of H. ammodendron to keep the hydraulic apparatus intact, even under extreme drought, may be related to variations of leaf and/or root morphology that relate to hydraulic architecture [45]. Dai [46] found that leaf area of $H$. ammodendron decreased continuously from July to August when upper-layer $(0-50 \mathrm{~cm})$ SWC (volumetric) was less than 3\%. On the other hand, Zou et al. [47] found higher leaf area per branch for H. ammodendron under double precipitation treatment than that under no precipitation treatment. Xu et al. [44] reported that shoot and root hydraulic conductance were equally important for water transport, and concluded that a decrease in leaf area (leaf shedding) was responsible for the decrease of shoot hydraulic resistors of H. ammodendron. These studies showed that adjustment of morphology that relates to hydraulic architecture is a dominant mechanism for H. ammodendron to maintain its hydraulic apparatus intact and survive under extreme drought. 
Throughout the four-year study period of the second half growing season, we revealed positive linear correlation between K and SWC and progressive inter-annual variation of stomatal behavior from more anisohydric to more isohydric at lower SWC, during prolonged droughts. These results will enrich our knowledge on coordinated regulation between soil water content and climate on canopy transpiration, deepening the understanding of flexible stomatal regulation on the survival of plants under annual prolonged drought in arid areas. Considering the apparent inter-annual variation in adaptive response in the water relations of $H$. ammodendron during prolonged drought, long-term studies are necessary for a better description of desert ecosystem physiology and how they may respond to future climate changes.

\section{Conclusions}

During prolonged droughts, $3 \%$ is the lower soil water threshold, below which H. ammodendron lost its ability to stomatally regulate water loss, subjecting it to mortality risk. Above this threshold, SWC had a positive linear correlation with transpiration sensitivity to VPD (K). The indirect effect of SWC on canopy transpiration through VPD could only be found on a long-term (inter-annual) scale. Stomatal behavior of $H$. ammodendron progressively shifted from more anisohydric to more isohydric, with decreasing SWC during prolonged drought when soil water content was above the lower threshold. The influence of SWC on K was linked to different stomatal behaviors in order to regulate water loss and ensure the survival of H. ammodendron, depending on drought intensity and duration. The flexible stomatal response to environment and the regulation of water loss is a key mechanism for $H$. ammodendron to balance production when soil moisture was attractable with survival when soil moisture was more limiting. Our results emphasized the importance of long-term observations of the interaction between plant water relations and the environmental variables and underlying adaptive mechanisms in arid lands.

Acknowledgments: This study was partly supported by the JSPS project (Grant No. 25302001). We thank Jia Jin, $\mathrm{Lu} \mathrm{Xu}$ and Bin Liu for their valuable assistance during fieldwork.

Author Contributions: Q.W. conceived and designed the experiments; D.G. performed the experiments; D.G. analyzed the data; D.G., D.O. and Q.W. wrote the paper.

Conflicts of Interest: The authors declare no conflict of interest.

\section{References}

1. Giorgi, F. Climate change hot-spots. Geophys. Res. Lett. 2006, 33, L08707. [CrossRef]

2. Dyurgerov, M.B.; Meier, M.F. Twentieth century climate change: Evidence from small glaciers. Proc. Natl. Acad. Sci. USA 2000, 97, 1406-1411. [CrossRef] [PubMed]

3. Shi, Y.; Shen, Y.; Kang, E.; Li, D.; Ding, Y.; Zhang, G.; Hu, R. Recent and future climate change in northwest China. Clim. Chang. 2007, 80, 379-393. [CrossRef]

4. Sorg, A.; Bolch, T.; Stoffel, M.; Solomina, O.; Beniston, M. Climate change impacts on glaciers and runoff in Tien Shan (Central Asia). Nat. Clim. Chang. 2012, 2, 725-731. [CrossRef]

5. Lal, M.; Harasawa, H. Future climate change scenarios for asia as inferred from selected coupled atmosphere-ocean global climate models. J. Meteorol. Soc. Jpn. Ser. II 2001, 79, 219-227. [CrossRef]

6. Chou, C.; Chiang, J.C.H.; Lan, C.-W.; Chung, C.-H.; Liao, Y.-C.; Lee, C.-J. Increase in the range between wet and dry season precipitation. Nat. Geosci. 2013, 6, 263-267. [CrossRef]

7. Farquhar, G.; Richards, R. Isotopic composition of plant carbon correlates with water-use efficiency of wheat genotypes. Funct. Plant Biol. 1984, 11, 539-552. [CrossRef]

8. Jasechko, S.; Sharp, Z.D.; Gibson, J.J.; Birks, S.J.; Yi, Y.; Fawcett, P.J. Terrestrial water fluxes dominated by transpiration. Nature 2013, 496, 347-350. [CrossRef] [PubMed]

9. McDowell, N.; Pockman, W.T.; Allen, C.D.; Breshears, D.D.; Cobb, N.; Kolb, T.; Plaut, J.; Sperry, J.; West, A.; Williams, D.G.; et al. Mechanisms of plant survival and mortality during drought: Why do some plants survive while others succumb to drought? New Phytol. 2008, 178, 719-739. [CrossRef] [PubMed] 
10. Allen, C.D.; Macalady, A.K.; Chenchouni, H.; Bachelet, D.; McDowell, N.; Vennetier, M.; Kitzberger, T.; Rigling, A.; Breshears, D.D.; Hogg, E.T. A global overview of drought and heat-induced tree mortality reveals emerging climate change risks for forests. For. Ecol. Manag. 2010, 259, 660-684. [CrossRef]

11. Hartmann, H.; Ziegler, W.; Kolle, O.; Trumbore, S. Thirst beats hunger-declining hydration during drought prevents carbon starvation in norway spruce saplings. New Phytol. 2013, 200, 340-349. [CrossRef] [PubMed]

12. Dai, Z.; Edwards, G.E.; Ku, M.S. Control of photosynthesis and stomatal conductance in Ricinus communis L. (castor bean) by leaf to air vapor pressure deficit. Plant Physiol. 1992, 99, 1426-1434. [CrossRef] [PubMed]

13. Tardieu, F.; Simonneau, T. Variability among species of stomatal control under fluctuating soil water status and evaporative demand: Modelling isohydric and anisohydric behaviours. J. Exp. Bot. 1998, 49, 419-432. [CrossRef]

14. McDowell, N.G. Mechanisms linking drought, hydraulics, carbon metabolism, and vegetation mortality. Plant Physiol. 2011, 155, 1051-1059. [CrossRef] [PubMed]

15. Oren, R.; Sperry, J.S.; Katul, G.; Pataki, D.; Ewers, B.; Phillips, N.; Schäfer, K. Survey and synthesis of intra-and interspecific variation in stomatal sensitivity to vapour pressure deficit. Plant Cell Environ. 1999, 22, 1515-1526. [CrossRef]

16. Rogiers, S.Y.; Greer, D.H.; Hatfield, J.M.; Hutton, R.J.; Clarke, S.J.; Hutchinson, P.A.; Somers, A. Stomatal response of an anisohydric grapevine cultivar to evaporative demand, available soil moisture and abscisic acid. Tree Physiol. 2012, 32, 249-261. [CrossRef] [PubMed]

17. Bourne, A.E.; Haigh, A.M.; Ellsworth, D.S. Stomatal sensitivity to vapour pressure deficit relates to climate of origin in Eucalyptus species. Tree Physiol. 2015, 35, 266-278. [CrossRef] [PubMed]

18. Cunningham, S. Stomatal sensitivity to vapour pressure deficit of temperate and tropical evergreen rainforest trees of Australia. Trees 2004, 18, 399-407. [CrossRef]

19. Lioubimtseva, E.; Henebry, G.M. Climate and environmental change in arid Central Asia: Impacts, vulnerability, and adaptations. J. Arid Environ. 2009, 73, 963-977. [CrossRef]

20. Zheng, C.; Wang, Q. Seasonal and annual variation in transpiration of a dominant desert species, Haloxylon ammodendron, in Central Asia up-scaled from sap flow measurement. Ecohydrology 2015, 8, 948-960. [CrossRef]

21. Zheng, C.; Wang, Q. Water-use response to climate factors at whole tree and branch scale for a dominant desert species in Central Asia: Haloxylon ammodendron. Ecohydrology 2014, 7, 56-63. [CrossRef]

22. Xu, H.; Li, Y.; Xu, G.; Zou, T. Ecophysiological response and morphological adjustment of two Central Asian desert shrubs towards variation in summer precipitation. Plant Cell Environ. 2007, 30, 399-409. [CrossRef] [PubMed]

23. Xu, G.-Q.; Li, Y.; Xu, H. Seasonal variation in plant hydraulic traits of two co-occurring desert shrubs, Tamarix ramosissima and Haloxylon ammodendron, with different rooting patterns. Ecol. Res. 2011, 26, 1071-1080. [CrossRef]

24. Liu, R.; Pan, L.-P.; Jenerette, G.D.; Wang, Q.-X.; Cieraad, E.; Li, Y. High efficiency in water use and carbon gain in a wet year for a desert halophyte community. Agric. For. Meteorol. 2012, 162-163, 127-135. [CrossRef]

25. Campbell, G.S.; Norman, J.M. An Introduction to Environmental Biophysics; Springer-Verlag: New York, NY, USA, 1998; p. 286.

26. Granier, A. Evaluation of transpiration in a douglas-fir stand by means of sap flow measurements. Tree Physiol. 1987, 3, 309-320. [CrossRef] [PubMed]

27. Granier, A.; Huc, R.; Barigah, S.T. Transpiration of natural rain forest and its dependence on climatic factors. Agric. For. Meteorol. 1996, 78, 19-29. [CrossRef]

28. Lide, D.R. Handbook of Chemistry and Physics; CRC Press: Boca Raton, FL, USA, 2010.

29. Law, B.; Falge, E.; Gu, L.; Baldocchi, D.; Bakwin, P.; Berbigier, P.; Davis, K.; Dolman, A.; Falk, M.; Fuentes, J. Environmental controls over carbon dioxide and water vapor exchange of terrestrial vegetation. Agric. For. Meteorol. 2002, 113, 97-120. [CrossRef]

30. Nicolás, E.; Barradas, V.; Ortuño, M.; Navarro, A.; Torrecillas, A.; Alarcón, J. Environmental and stomatal control of transpiration, canopy conductance and decoupling coefficient in young lemon trees under shading net. Environ. Exp. Bot. 2008, 63, 200-206. [CrossRef] 
31. Clausnitzer, F.; Köstner, B.; Schwärzel, K.; Bernhofer, C. Relationships between canopy transpiration, atmospheric conditions and soil water availability-Analyses of long-term sap-flow measurements in an old Norway spruce forest at the Ore Mountains/Germany. Agric. For. Meteorol. 2011, 151, 1023-1034. [CrossRef]

32. Jung, E.Y.; Otieno, D.; Lee, B.; Lim, J.H.; Kang, S.K.; Schmidt, M.W.T.; Tenhunen, J. Up-scaling to stand transpiration of an Asian temperate mixed-deciduous forest from single tree sapflow measurements. Plant Ecol. 2010, 212, 383-395. [CrossRef]

33. Chen, D.; Wang, Y.; Liu, S.; Wei, X.; Wang, X. Response of relative sap flow to meteorological factors under different soil moisture conditions in rainfed jujube (Ziziphus jujuba Mill.) plantations in semiarid northwest China. Agric. Water Manag. 2014, 136, 23-33. [CrossRef]

34. Daly, E.; Porporato, A. A review of soil moisture dynamics: From rainfall infiltration to ecosystem response. Environ. Eng. Sci. 2005, 22, 9-24. [CrossRef]

35. Cammalleri, C.; Rallo, G.; Agnese, C.; Ciraolo, G.; Minacapilli, M.; Provenzano, G. Combined use of eddy covariance and sap flow techniques for partition of ET fluxes and water stress assessment in an irrigated olive orchard. Agric. Water Manag. 2013, 120, 89-97. [CrossRef]

36. Xu, H.; Li, Y. Water-use strategy of three Central Asian desert shrubs and their responses to rain pulse events. Plant Soil 2006, 285, 5-17. [CrossRef]

37. Jiang, J. The physioecological characters of transpiration of two species of haloxylon. Arid Zone Res. 1992, 9 , $14-17$.

38. O'Grady, A.P.; Mitchell, P.J.; Pinkard, E.A.; Tissue, D.T. Thirsty roots and hungry leaves: Unravelling the roles of carbon and water dynamics in tree mortality. New Phytol. 2013, 200, 294-297. [CrossRef] [PubMed]

39. Plaut, J.A.; Wadsworth, W.D.; Pangle, R.; Yepez, E.A.; McDowell, N.G.; Pockman, W.T. Reduced transpiration response to precipitation pulses precedes mortality in a pinon-juniper woodland subject to prolonged drought. New Phytol. 2013, 200, 375-387. [CrossRef] [PubMed]

40. Hetherington, A.M.; Woodward, F.I. The role of stomata in sensing and driving environmental change. Nature 2003, 424, 901-908. [CrossRef] [PubMed]

41. Domec, J.C.; Johnson, D.M. Does homeostasis or disturbance of homeostasis in minimum leaf water potential explain the isohydric versus anisohydric behavior of Vitis vinifera L. cultivars? Tree Physiol. 2012, 32, 245-248. [CrossRef] [PubMed]

42. Lovisolo, C.; Perrone, I.; Carra, A.; Ferrandino, A.; Flexas, J.; Medrano, H.; Schubert, A. Drought-induced changes in development and function of grapevine (Vitis spp.) organs and in their hydraulic and non-hydraulic interactions at the whole-plant level: A physiological and molecular update. Funct. Plant Biol. 2010, 37, 98-116. [CrossRef]

43. Zhang, Y.; Oren, R.; Kang, S. Spatiotemporal variation of crown-scale stomatal conductance in an arid Vitis vinifera L. cv. Merlot Vineyard: Direct effects of hydraulic properties and indirect effects of canopy leaf area. Tree Physiol. 2012, 32, 262-279. [CrossRef] [PubMed]

44. Xu, G.; Li, Y.; Zou, T. Hydraulic resistance partitioning between shoot and root system and plant water status of Haloxyolon ammodendron growing at sites of contrasting soil texture. J. Arid Land 2010, 2, 98-106. [CrossRef]

45. Schafer, K.V. Canopy stomatal conductance following drought, disturbance, and death in an upland oak/pine forest of the New Jersey Pine Barrens, USA. Front. Plant Sci. 2011, 2, 15. [CrossRef] [PubMed]

46. Dai, Y. Precipitation Partitioning and Its Ecological Significance for Desert Dominant Species Haloxylon ammodendron and Haloxylon persicum. Ph.D. Thesis, University of Chinese Academy of Sciences, Beijing, China, 2015.

47. Zou, T.; Li, Y.; Xu, H.; Xu, G.-Q. Responses to precipitation treatment for Haloxylon ammodendron growing on contrasting textured soils. Ecol. Res. 2010, 25, 185-194. [CrossRef]

(C) 2017 by the authors. Licensee MDPI, Basel, Switzerland. This article is an open access article distributed under the terms and conditions of the Creative Commons Attribution (CC BY) license (http:/ / creativecommons.org/licenses/by/4.0/). 